\title{
Research on Recruitment and Performance Management of Electricity Sales Company Based on Competency Model
}

\author{
Xi Xingxuan \\ North China Electric Power University \\ Changping, Beijing, China \\ 15650756648@163.com
}

\begin{abstract}
The reform of the national electric power system has led to the establishment of a number of electricity sales companies. In the face of severe market competition, how to set up management of their own talent team is one of the key issues to solve the problem of lacking competitiveness. This paper is based on the competency model of job post and uses qualitative analysis method to study its application in the recruitment and performance management of the electricity sales company, and finds out the customer-oriented competency model based on the development strategy of sales company can play a key role in recruitment and performance management, which is conducive to the better management of the operation team, and transform the human resources advantages into the company's development advantages, laying a good foundation for its long-term profitability.
\end{abstract}

Keywords-competency model; electricity sales company; recruitment; performance management

\section{INTRODUCTION}

The country's new round of power system reform has been kicked off, and the market competition-oriented electricity sales companies have established, its human resources management is also different from the traditional state-owned power grid enterprises. The introduction of market competition after the sales companies in order to obtain profit not only to develop a variety of business, but also to actively explore sales, technology and other talents, setting up an excellent team of people and establish the own characteristics of recruitment, appointment, assessment and other aspects to attract the talent joining the industry. The competency model is based on the establishment of post competency, which plays a vital role in a series of processes of human resource management. This paper focuses on the establishment and application of competency model of electric power sales companies from the aspects of recruitment and performance management, and analysis the importance of the human resources management of the electricity sales company.

\section{CONSTRUCTION OF COMPETENCY MODEL OF ELECTRICITY SALES COMPANY}

A. The meaning of the establishment of competency model

Competency is an individual characteristic that is closely related to excellent performance in a particular work situation. It can be Motives, Traits, Social roles, Self-concepts, Knowledge and Skill.

Competency characteristics are closely related to employee performance and can predict the future performance of employees, which is conducive to the rational allocation of staff work; it can distinguish between good employees and general staff; and job requirements and organizational environment linked to a dynamic change nature.

The level of competency can be represented by an iceberg model:

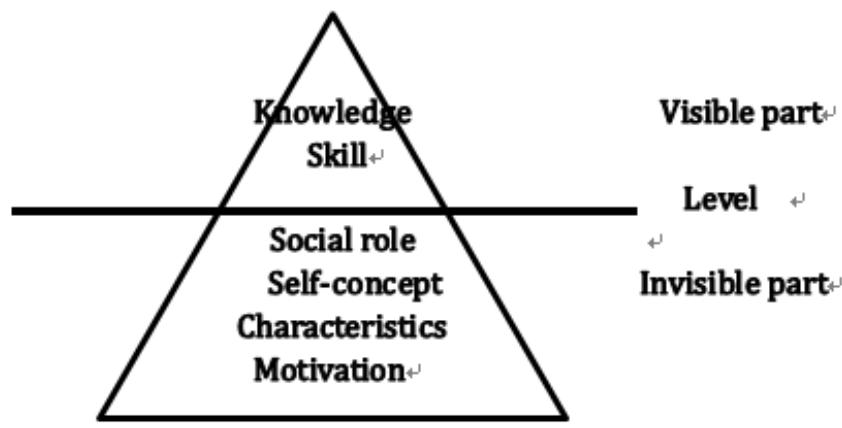

Fig. 1. The iceberg model of competency

The iceberg model clearly shows the visible features: knowledge, skills are easy to develop, easy to observe, easy to evaluate, which are directly used to complete different tasks; and those are not visible: social roles, self-concept, characteristics, motivation is implicit, long-term formation and difficult to change, not easy to observe the evaluation, and cannot be used directly to complete the characteristics of different work, but a deeper role in determining.

At present, the majority of enterprise managers move the focus of the enterprise human resource management work 
forward, from the post-management to pre-management, and improve the management efficiency of talent's "election, education, use, stay" all aspects. The recruitment evaluation, training and development, performance appraisal, salary incentive and other work are combined together, and the management of human resources in enterprises has been raised to a new level, which has laid a solid foundation of talent for the development of enterprises. The enterprise mission, vision and values can be converted into specific norms, make employees understand the recognition and action, so that corporate culture really play a role in inspiring, and ultimately enhance the staff, department and organizational performance to achieve the strategic objectives of the enterprise [1].

Therefore, the use of competency model for staff recruitment and performance management can greatly improve the efficiency and level of human resources management of the company, and meet the needs of the company's complex talents, making the company in the market leading position.

\section{B. Construction of competency model}

\section{1) Behavioral Event Interview}

Behavioral interview method refers to the interview method to obtain the main purpose of the interviewee behavior which is more to get the information of respondents how to act In the implementation of the behavior of the interview, the use of STAR to carry out the details of the question is more easily to identify the authenticity of the interviewee, while the description of some cases can be extracted some of the quality of competencies, such as the interviewer constantly stressed the communication skills, patience, sense of responsibility, teamwork, and the ability to identify problems [2]

\section{2) Questionnaire survey method}

Questionnaires are a way to collect research data from research subjects in written form with rigorous design of mental measurement items or questions. The questionnaire can collect a large amount of information and data at the same time and evaluate the model in a large crowd. How to make the next evaluation should be added to the feedback of the competency model. The questionnaire should not be designed independently, and it should be used in conjunction with interview and data analysis, and the reliability of the questionnaire should be tested. In order to ensure the reliability, effectiveness and stability of the questionnaire, the reliability test should be carried out to check the relevance, consistency and significance of the questionnaire.

\section{3) Work Analysis}

It is very necessary to establish the competency model based on job analysis. Through the analysis of job responsibilities, working hours, working conditions and work intensity, the competency model is accurate and perfect, and it is more quantitative and scientific. The method of job analysis used to construct the competency model should be distinguished from the traditional approach, and the focus of the analysis should be on the analysis of human activities, the identification of job requirements and the ability to differentiate.

\section{Development Strategy of Electricity Sales Company}

The ultimate purpose of electricity sales company is profit, so it will meet the individual needs of users, focusing on clean energy-saving, sales of Internet, strengthening market competition, developing innovative business. Its overall strategic goal is to accelerate the development of the electricity industry, expand the power sales business focus on solving the electricity autonomy, energy saving, efficient, and provide users with high quality, convenient and economical services. The characteristics of electricity sales company determine their customer first and sales-oriented business philosophy.

\section{The Talent that the Electricity Sales Company Needs}

- Electricity sales staff. From the nature of the company, electricity sales company's sales staff should be relatively large; from the grassroots level sales staff to high-level sales managers.

- Computer practitioners with background knowledge of electric energy. In order to reduce the electricity sales companies trading margin of the marginal error, they can make mathematical modeling and accord to the weather and other factors to accurately predict the customer's electricity demand (such as cold or high temperature on the user's electricity demand).

- Electric energy price program designer. Good marketing price program can guide users to establish a good time using electricity habits, but also can improve the company's own market share and profit margins, reduce the operational risk in the electricity market.

- The development of new energy equipment, operation and maintenance staff. The sale of electricity companies not only have the sale of electricity business, but also may be more involved in energy-saving, intelligent power system equipment development and sales in the future.

\section{E. The Electricity Sales Company's Sales Staff Competency Model}

Sales staff is the most important staff of the sale of electricity companies, competency model established with the development of long-term goal from the enterprise, and meet with corporate values, business philosophy and other closely integrated to the company's overall strategy development. First, the business philosophy and development strategy of the electricity sales company determine the competency model of the sales post in the key positions of the organization, that is, we will be able to meet the needs of different customers, design the most personalized service plan for customers, and attract more customers.

Second, to have teamwork and innovation, we must have a strong achievement motivation and actively seize the market opportunities. We also need constantly open up new business to unite the entire sales team and make common progress. From interpersonal influence, achievement motivation, as well as the team leader, logical, analytical thinking, initiative, develop others, customer service consciousness, self- 
confidence, etc. for quality in the choice to establish the most suitable for our company competence quality model of different job positions.

\section{THE APPLICATION OF COMPETENCY MODEL IN RECRUITMENT}

Based on the competency of the recruitment is based on the target position on the competency of the various requirements as the basis, and change the traditional selection of talent with experience but according to the competency model developed by the interview evaluation and the results of this questionnaire as a recruitment tool of scientific and reasonable recruitment management activities [3]

In the recruitment, the electricity sales company should pay more attention to the intrinsic quality of candidates, develop the potential of employees. The traditional interview method attached to the external quality of staff and work experience description of the intrinsic quality while the discovery is very limited. The electricity sales company's business provides personalized energy packages, energysaving service packages, power sharing, etc., which largely need talent understanding or having engaged in the power industry-related work experience.
The electricity sales company can use the behavioral interview method to recrue the interview when the staff recruited, and compare the candidates to find out whether the candidate has the competency quality described in the competency model. That is, the candidates describe specific issues in the specific success or failure of the incident, and the interviewer ask a detailed question on the power market professional issues, so as to understand the real situation of candidates. [4] And then according to the characteristics of the candidates and the needs of their work, placing them in the right position, so that each employee can play his greatest value in his position

Most of the current market electricity sales companies in the senior job recruitment are generally required to familiar with the operation of the power system and the power company's overall mode of operation, with power transactions, power distribution, power demand side management, power production planning and other professional technical capacity and rich market expansion, business negotiations, large customer management and other power system marketing experience. We can see that these are the needs of senior personnel of the sale of electricity companies, which can be layered to the grassroots sales staff recruitment requirements and establish different grades competency model. Fig2 is the recruitment process based on the competency model.

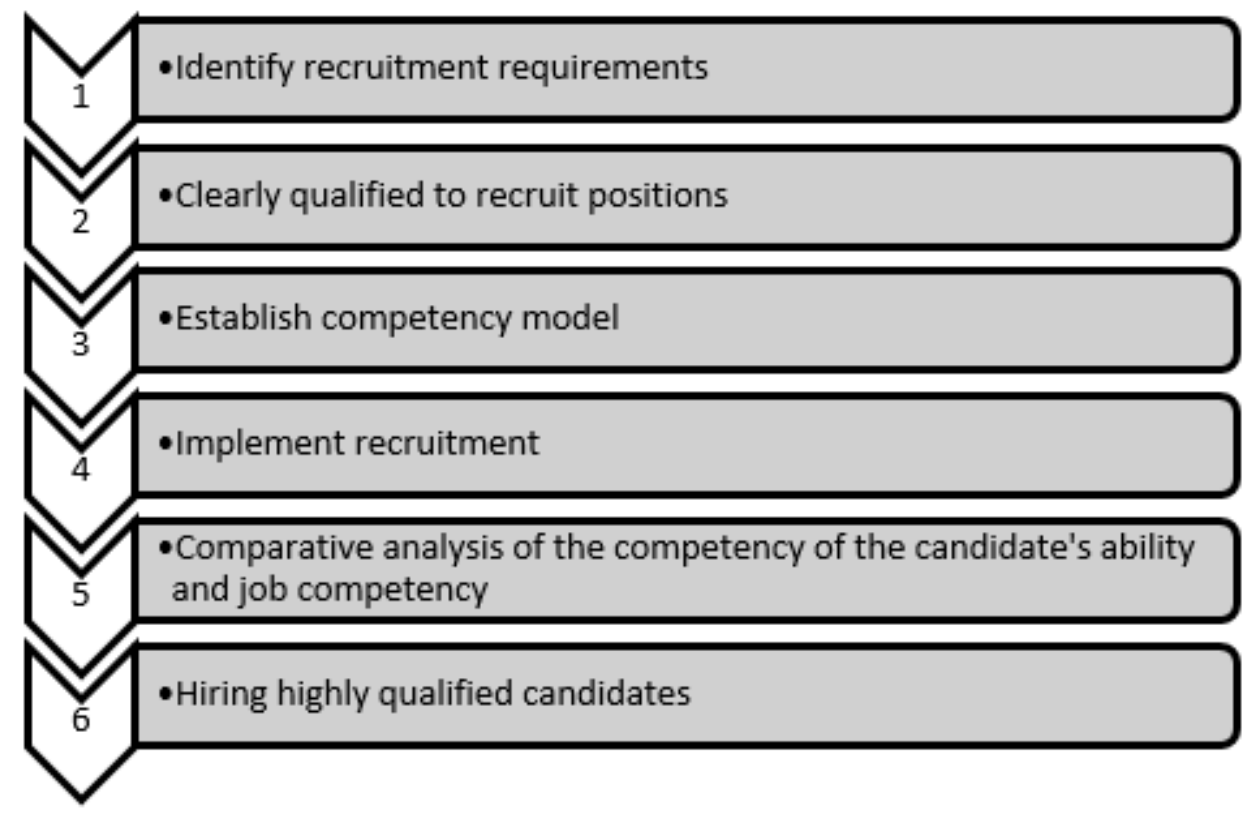

Fig. 1 Based on the competency model of the recruitment process

\section{THE APPLICATION OF COMPETENCY MODEL IN PERFORMANCE MANAGEMENT}

Electricity sales company is faced with market competition environment, and it do not have business advantages, so it cannot use the traditional power management thinking method to consider performance management. Especially in the limited profit margins, the premise of performance management is especially important if company want to survive in the market competition and make development.
The competency model applied to performance management not only focuses on explicit performance indicators, but also focuses on the impact of competency on job performance. Scientific performance appraisal mechanism and system can correctly assess the talent, establish a reasonable incentive mechanism and supervision mechanism for salary management, job adjustment, promotion, recruitment and other aspects to provide the necessary basis [5]. 
Competency model can help sales companies to establish employee behavior norms, while employees can clear their work direction and achieve the performance. As the sale of electricity companies in the market competition is the main part, they should abandon the traditional state-owned enterprises and strict with the market mechanism, introducing competition in the talent management mechanism, scoring fairly of impartial performance and pay incentives to improve the overall team vitality and efficiency [6].

Performance feedback after performance evaluation is also a key link in performance management. Performance feedback can further confirm the rationality of competency and prove the correctness of the quality model or unreasonable to adjust the improvement. At the same time, after a period of running and inspection, doing some adjustments to those who do not meet the job requirements of staff in a timely manner to adjust the post can achieve the optimal allocation of staff of the dynamic management. The staff can make potential maximum development and play personal value in the meanwhile.

\section{CONCLUSION}

The new establishment of the electricity sales company's human resources management system should be different from the traditional power companies, but also to distinguish with ordinary commodity trading enterprises. In order to occupy a place in the fierce market competition, the companies need innovative management and the establishment of reasonable human resources management system to introduce and retain talents. Competency model has a high value in discovering quality, and is very effective in explaining the relationship between quality and behavior, so it has a guiding role in achieving higher performance. The use of competency model can provide a strong reference and management basis for the recruitment and performance management of electricity sales companies. Only by improving the internal management of the electricity sales company, can we take more customer resources and increase market share in market competition and gain a great momentum of development.

\section{REFERENCES}

[1] Hu Bingdong. Through the competency model to build a new system of human resources management. North China Electric Power University .2007

[2] Lu Xinhua.Study on the Construction of Project Team Competency Model. Jilin University

[3] Kong Lingzhi.Study on Human Resource Management Model of Water Conservancy Construction Project Based on Competency. North China Electric Power University .2010

[4] Jin Zuoyan on the recruitment of competency analysis. [J] Journal of Beijing Vocational College of Labor and Social Security. Vol.56.2007.1, pp18

[5] Li Xiaoning, Dai Yan, Xie Yantao. Power enterprise human resources management status analysis. "Engineering Technology: Full Version" Vol.25.2017.4pp192

[6] Zhao Haoliang. State-owned enterprise reform in the wave of human resources status and strategy research. "Electric power and energy" Vol.37.2016. 1pp153-156 